\title{
Da formação humanística do mediador cultural Ozildo Albano às suas práticas educativas no sertão piauiense (1952-1989)
}

\author{
From the humanistic formation of the cultural mediator Ozildo Albano to his educative practices in \\ the Piaui Sertão (1952-1989)
}

De la formation humaniste du médiateur culturel Ozildo Albano à ses pratiques éducatrices dans le Piaui Sertão (1952-1989)

Welbert Feitosa Pinheiro ${ }^{1}$

Universidade Federal de Uberlândia

Sônia Maria dos Santos ${ }^{2}$

Universidade Federal de Uberlândia

Resumo: O presente artigo trata do processo formativo e das práticas educativas do educador Ozildo Albano, evidenciadas entre os anos de 1952 a 1989, no Piauí. Buscou-se apresentar o modo de formação humanística por ele recebido, do ambiente familiar à universidade, e como isso refletiu em suas práticas educativas, nos vários espaços em que atuou, da escola fundada por ele ao museu no qual organizou. Adotou-se como suporte teórico Bourdieu (2006, 2007), Sirinelli (2003), Pomian (1984) e Eco (1993, 1994).

Palavras-chave: Formação humanística. Prática educativa. Mediador cultural

Summary: This article deals with the formative process and educative practices of the educator Ozildo Albano, evidenced between the years 1952 to 1989, in Piauí. It was sought to present the way of humanistic formation he received, from the family environment to the university, and how this reflected in his educational practices, in the various spaces in which he acted, from the school he founded to the museum in which he organized. It was adopted as theoretical support Bourdieu (2006, 2007), Sirinelli (2003), Pomian (1984) and Eco (1993, 1994).

Keywords: Humanistic formation. Educational Practice. Cultural mediator

Résumé: Cet article traite du processus de formation et des pratiques éducatives de l'éducateur Ozildo Albano, attesté entre les années 1952 à 1989, à Piauí. Il a été cherché à présenter la voie de la formation humaniste qu'il a reçu, de l'environnement familial à l'Université, et comment cela reflétait dans ses pratiques éducatives, dans les différents espaces dans lesquels il a agi, de l'école qu'il a fondée au musée dans lequel il s'est organisé. Il a été adopté comme support théorique Bourdieu (2006, 2007), Sirinelli (2003), Pomian (1984) et $\operatorname{Eco}(1993,1994)$.

Mots-clés: Formation humaniste. Pratique éducative. Médiateur culturel

\footnotetext{
1 Doutorando em Educação no Programa de Pós-Graduação em Educação da Universidade Federal de Uberlândia. Universidade Federal de Uberlândia - PPGED.E-mail: welbertfp@hotmail.com

${ }^{2}$ Doutora em Educação. Professora do Programa de Pós-Graduação em Educação da Universidade Federal de Uberlândia. Universidade Federal de Uberlândia - PPGED.E-mail: soniaufu@gmail.com
} 


\section{Introdução}

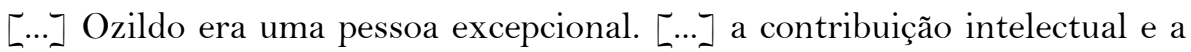
presença humana dele constituíam um patrimônio que destacava Picos, culturalmente, dentro do Piauí, a par da sua reconhecida importância econômica. Qual outra cidade piauiense tinha, entre os seus filhos, uma pessoa que reunia, ao mesmo tempo, a vocação de pesquisador, historiador, memorialista e colecionador? (Renato Duarte)

É com as palavras do historiador picoense Renato Duarte, publicado no Jornal Gazeta Popular, em 19 de julho de 1989, que se apresenta ao leitor o educador José Albano de Macedo, conhecido em vida por Ozildo Albano. Nascido em 20 de novembro de 1930 em terras picoenses. Tornou-se um dos piauienses mais ilustres por sua capacidade de olhar para o passado e extrair um campo de pesquisa.

Ozildo Albano tornou-se um nome representativo da história e da cultura local. Recebeu da sua gente o respaldo para ocupar o grupo seleto da intelligentsia piauiense. E, a partir daí, adentrou ao campo de produção simbólica e passou a fazer a mediação cultural em contextos sociais fortemente marcados pelo distanciamento do poder público frente à escolarização.

O nome de Ozildo Albano delimitou espaços e marcou a geração daqueles que conviveram com ele. Mais precisamente, como destaca Bourdieu (2006, p.187):

[...] O nome próprio é o atestado visível da identidade do seu portador
através dos tempos e dos espaços sociais, o fundamento da unidade de suas
sucessivas manifestações e da possibilidade socialmente reconhecida de
totalizar essas manifestações em registros oficiais, curriculum vitae,
cursushonorum, ficha judicial, necrologia ou biografia, que constituem a vida
na totalidade finita, pelo veredicto dado sobre um balanço provisório ou
definitivo. [...].

Em diálogo com Bourdieu (2006), percebe-se que o nome faz parte da personalidade e, como tal, é socialmente construído por meio dos tempos e dos espaços sociais. Ozildo Albano foi detentor de um nome que se fez por intermédio de um capital cultural institucionalizado e de um capital cultural de autoconstituição.

Entendendo aqui o termo capital cultural, utilizado por Bourdieu (2007, p.75), como sendo: 
[...] um ter que se tornou ser, uma propriedade que se fez corpo e tornou-se parte integrante da 'pessoa', um habitus. Aquele que o possui 'pagou com sua própria pessoa' e com aquilo que tem de mais pessoal, seu tempo. [...].

Ozildo Albano se apropriou de bens culturais que deram a ele notoriedade em diversas áreas do conhecimento humano, dentre elas, a literatura, filosofia, teologia, história, artes, folclore, música, doutrina jurídica.

\section{A trajetória formativa de Ozildo Albano e a constituição do educador}

Educado numa família humilde e de forte tradição católica, Ozildo Albano foi uma criança que aprendeu os valores humanos e cristãos no convívio diário com os seus pais Manoel Albano da Silva e Neomísia Macedo Albano.

Ozildo Albano viveu em um meio social em que se cultivavam as raízes folclóricas e os costumes locais. Foi uma criança que aprendeu a valorizar tudo que estava a sua volta e participava, como as demais crianças de sua época, ativamente da vida interiorana.

Nos encontros familiares, nas localidades Tanque, Curralinho e Sítio Palmeira, pertencentes ao município de Picos, Ozildo Albano se mantinha atento às histórias narradas pelos seus familiares em torno das práticas cotidianas que pontuaram os afazeres agrícolas e das moagens que realizavam.

Ozildo Albano, além de herdar do seu pai o gosto pela música e o jeito simples de ser, herdou também a capacidade que tinha de dosar o discurso cotidiano com o anedotário do homem local.

Significativamente, a educação religiosa foi um dos pilares na formação humanística de Ozildo Albano. Aprendeu com os seus pais os princípios cristãos que deveriam nortear o homem em sociedade. Para tanto, participava com os seus irmãos e primos das missas e dos eventos religiosos que eram realizados na Igreja Católica de Picos. A irmã de Ozildo Albano, a professora Maria da Conceição Silva Albano, em entrevista realizada em 14.02.2017, assim relatou:

Meus pais eram religiosos e a religião católica predominava em todos os lares. Naquele tempo, tinha as novenas, as missas, tinha a primeira comunhão e eram muito fortes as festas religiosas. [...] As crianças acompanhavam os pais nas novenas do interior. […] Quase não tinha tanta diversão. [...] Eles encaminhavam a gente, mas não éramos obrigados a ter que ir. [...] Não tinha isso do vai ter que ir. Nossos pais deixavam a gente a vontade, com liberdade para escolher. Agora, terminava ali porque os 
outros primos também estavam ali, os amigos da escola também estavam ali, num evento e assim como na missa. Era o contexto da realidade de Picos daquela época.

A religiosidade fazia parte da vida social de Ozildo Albano. Um dos registros que marcou a sua trajetória humana foi a sua primeira eucaristia realizada em 1938. Isso fazia parte da educação religiosa que os seus pais proporcionavam para ele e os seus irmãos.

No mesmo ano em que Ozildo Albano fez a primeira eucaristia, os seus pais matricularam-no na Escola Municipal Landri Sales. Foi nesta escola em que ele deu início a sua formação primária e que teve Hilda Policarpo de Mello como primeira professora.

Foi com Hilda Policarpo de Mello que Ozildo Albano se interessou mais ainda pelas leituras. Ela tinha por hábito colocar os alunos para lerem os textos do livro Coração de Criança e Ozildo Albano fazia com muita eficiência e percorria o texto sem nenhuma dificuldade. Segundo o amigo de sala de aula dos tempos do primário, Elízio Serafim de Souza:

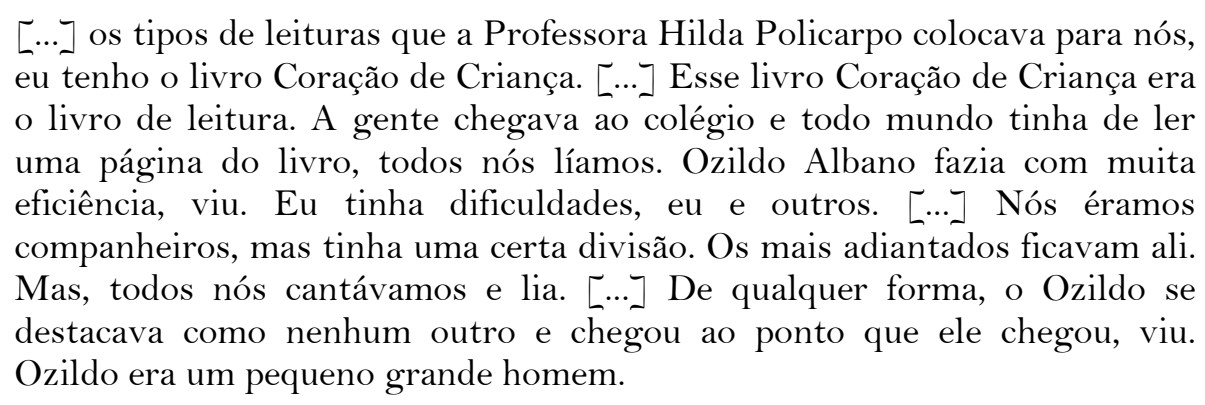

Outras professoras também fizeram parte da formação primária de Ozildo Albano. Destacam-se a professora Maria de Jesus Santos, que substituiu a professora Hilda Policarpo de Mello.

O Grupo Escolar Coelho Rodrigues foi uma nova experiência na vida de Ozildo Albano e isso foi tão marcante para ele que manteve consigo as fotografias de todas as professoras dessa tradicional instituição escolar. Dentre elas, Benvida Nunes Santos, Ricardina de Castro Neiva e Luiza Maia da Silva Campos.

No processo de formação de Ozildo há de se fazer um registro em torno da sua formação cristã. Foi com as primeiras lições religiosas que Ozildo Albano recebeu de seus pais os dogmas católicos que o impulsionou a ingressar no Seminário Coração de Jesus, em Teresina, capital do Piauí. Por lá, ele ampliou a sua visão de mundo e participou de um universo de aprendizagem completamente diferente do que se tinha na sua terra natal. 
O seminário foi um espaço em que Ozildo Albano se dedicou aos estudos do evangelho e ao encontro com a formação clássica, uma vez que entrou em contato com o idioma latim, a história e a filosofia.

Em 1948, Ozildo Albano desistiu do internato para se tratar de uma pneumonia que estava prejudicando a sua saúde e, por orientações médicas, não retornou mais para o Seminário Sagrado Coração de Jesus. Mas, o fato é que os anos em que esteve em Teresina foram de muita dedicação aos estudos e renderam uma bagagem de conhecimentos que sedimentaram a sua trajetória humana.

Em 1949, Ozildo Albano passou por uma nova etapa na sua vida, ingressou no Tiro de Guerra 201. Essa formação militar deu a ele não só habilidades para manusear armas e lidar com situações limites, mas também, disciplina e aprendizado necessários para atuar em diferentes áreas do conhecimento humano.

Na guarnição, Ozildo Albano era respeitado pelos colegas que serviram com ele. Polido nas suas expressões e no trato humano para com todos, chamou a atenção dos seus superiores que deram a ele as atribuições de guarda e organização dos arquivos da corporação.

No Tiro de Guerra 201, Ozildo Albano sabia o nome e o número de todos que estavam servindo e não se descuidava dos instrumentos que estavam sobre sua guarda e proteção. Era requisitado por seus colegas quando tinham alguma dúvida sobre assuntos relacionados aos trabalhos dentro da corporação.

E foi no mesmo ano que encerrou o cumprimento das suas obrigações frente ao Tiro de Guerra 201 que Ozildo Albano prestou o exame de admissão para ingressar no Ginásio Estadual Picoense.

Em 1950, Ozildo Albano foi aprovado no exame de admissão e matriculou-se no Ginásio Estadual Picoense. A sua formação ginasial foi marcada por intensa atividade escolar. Foi o primeiro presidente do Grêmio Literário Da Costa e Silva e, juntamente com professores e colegas ginasianos, empreenderam esforços para adquirirem uma máquina tipográfica para impressão de um jornal estudantil.

Vale destacar que Ozildo Albano foi o estudante responsável em comprar a máquina tipográfica em Recife, capital de Pernambuco. Quando retornou, criaram o jornal Flâmula e o seu primeiro exemplar circulou no município de Picos em 15 de março de 1952.

Ozildo Albano foi o primeiro gerente do Jornal Flâmula e se encarregou também de fazer as correções deste periódico. E mais ainda, mantinha uma coluna chamada "Grandes 
Datas”. E, desta escrita jornalística, desenvolvia as suas práticas educativas, educando o público leitor através do material histórico que continha em cada texto que publicava nas páginas de Flâmula.

Ozildo Albano propagava conhecimentos e esperava dos seus leitores movimentos interpretativos que permitissem compreender a sua proposta textual. Agia, assim, porque o contexto social de Picos dos anos 1950 era de um município tangido pelo atraso educacional e que necessitava de um despertar por parte da população.

Nos textos que lançava na sua coluna "Grandes Datas" continha o que queria que o seu leitor-modelo entendesse. E, assim, Ozildo Albano estava construindo o seu leitor. Ou, como afirma Eco (1993, p.59), "[...] prever o próprio leitor-modelo não significa apenas 'esperar' que exista, significa também conduzir o texto de forma a construí-lo”.

Ozildo Albano conhecia a espacialidade em que o Jornal Flâmula circulava e sabia também do nível educacional e cultural do público leitor. Para tanto, se apoiava em textos que permitissem conduzir o leitor a encontrar as chaves de leituras. E, assim fazendo, estaria cumprindo a proposta de Eco (1994, p.99) para quem “[ [...] o perfil do leitor-modelo é desenhado pelo texto e dentro do texto".

Depois que concluiu o Ginásio Estadual Picoense, Ozildo Albano mudou-se para Fortaleza, capital do Ceará, e residiu na Casa do Estudante. Em 1954, ele ingressou no Colégio Estadual do Ceará, onde teve a sua formação secundária.

Foi no Colégio Estadual do Ceará que Ozildo Albano se deparou com uma nova realidade social. Por lá, construiu novas amizades, participou de eventos e viveu momentos de aprendizagens.

Em 1957, participou do vestibular na Universidade Federal do Ceará e conseguiu ser aprovado para o curso de Direito. A sua formação acadêmica foi marcada por muitas leituras e participações em eventos jurídicos e escreveu o seu nome em uma das mais concorridas instituições de ensino superior no Brasil.

Formou-se no ano de 1961 e trouxe para a sua terra natal uma bagagem jurídica repleta de conhecimentos em diferentes áreas do Direito. Advogou pouco porque em 04 de fevereiro de 1964 foi aprovado para a magistratura piauiense e assumiu uma comarca de primeira entrância no município de Pio IX, no Piauí.

Depois que retornou de Fortaleza e fixou-se em Picos, Ozildo Albano e sua irmã, Maria da Conceição Silva Albano, resolveram criar, em 1962, o Instituto Padre José de Anchieta. 
Era uma escola de qualidade e que se voltava para a formação humana de crianças e jovens. Tinha a alfabetização, o $1^{\circ}$ até o $4^{\circ}$ ano e o preparatório para o exame de admissão ao ginásio, que tinha como um dos professores Ozildo Albano.

O professor Ozildo Albano permaneceu com as suas práticas educativas no Instituto Padre José de Anchieta entre 1962 e 1963 e em fevereiro de 1964 assumiu o cargo de Juiz de Direito no vizinho município de Pio IX.

Vale lembrar de que o período em que ficou no Instituto Padre José de Anchieta, Ozildo Albano educou os filhos dos picoenses não só nas dependências da sua escola, como também em eventos fora da escola, os quais eram organizados por ele. Dentre esses eventos registram-se as quadrilhas juninas, a celebração da páscoa, os desfiles de sete de setembro e as comemorações do dia da árvore e de outras datas que faziam parte do calendário de sua escola.

No mesmo ano em que criou o Instituto Padre José de Anchieta, Ozildo Albano foi convidado para assumir a direção e lecionar no antigo Colégio Comercial de Picos. Por lá, ele também marcou uma etapa importante na história da educação picoense, pois, utilizou de práticas educativas que motivavam os seus alunos na busca pelo conhecimento. Ele levava os alunos do Colégio Comercial de Picos para recitarem e encenarem peças teatrais no auditório do Instituto Monsenhor Hipólito. Segundo as declarações de Vanilda (22.11.2017),

As aulas do professor Ozildo eram motivadas. [...] Ele era aquele professor amigo, que conquistava. Não fazia distinção de aluno, ele não tinha distinção de raça, cor, credo religioso. [...] Ele inovava, a didática dele era de dons, de ser professor. Acho que ele já nasceu com o dom de ser educador. [...] Ele procurava educar o aluno em todos os sentidos, moralmente, civilmente. Ele se entregava no que ele fazia. Tudo que ele ia fazer, ele fazia com amor e sabendo o que estava fazendo. Durante a vida dele, o que ele procurou fazer foi de vocação e amor à profissão. [...] $\mathrm{O}$ maior dom que Ozildo tinha era de ser educador.

A fala da ex-aluna de Ozildo Albano informa muito sobre Ozildo Albano e suas práticas educativas. Mas, mais ainda, aponta quem foi o intelectual picoense que levou saberes diversos, por meio de uma didática inovadora, para seus alunos.

Em março de 1964, Ozildo Albano assumiu o magistério e foi diretor no Ginásio Francisco Suassuna de Melo, em Pio IX. Era um educador muito respeitado pelos picoenses, todos o admiravam pelo seu jeito simples e humilde. Promoveu vários eventos culturais, encenou peças teatrais e montou quadrilhas juninas que chamaram a atenção do público. 
Em junho de 1966, Ozildo Albano foi promovido para assumir a comarca de Jaicós, no Piauí. Além das atribuições judicantes, ele foi convidado para assumir turmas no Ginásio Padre Marcos. E foi neste ginásio que Ozildo Albano continuou no exercício de suas práticas educativas e envolveu alunos e a comunidade local. Os seus ex-alunos até hoje lembram das suas aulas e do educador amigo que esteve lecionando em terras jaicoenses.

Depois da sua aposentadoria em 1969, Ozildo Albano retorna a Picos e dá prosseguimento as suas atividades docentes. Foi nomeado para lecionar no Complexo Escolar de Picos as disciplinas de Estudos Sociais, nomeado através de duas portarias $n^{\circ}$ 235/74 e a portaria $\mathrm{n}^{\mathrm{o}} \mathrm{02646/75.}$

Durante o tempo em que esteve lecionando no Complexo Escolar de Picos, Ozildo Albano foi um professor que se destacou pela sua capacidade de transformar o ambiente de sala de aula em um laboratório de conhecimentos.

Os seus ex-alunos lembram dele de uma forma muito carinhosa. Tinha-o como um intelectual disposto a ajudá-los no que tivesse ao seu alcance. Ele ainda colocava o seu museu particular à disposição daqueles que quisessem fazer pesquisas não só de disciplinas que lecionava, como também das outras disciplinas escolares.

Por derradeiro, há de se destacar que não se esgotaram aqui as práticas educativas do educador Ozildo Albano. Ele percorreu por muitas outras formas de educar os sujeitos do seu tempo. Viveu a maior parte da sua história de vida no interior do Piauí, em especial no município de Picos, onde construiu amizades e tornou-se um dos maiores arautos da cultura local.

\section{As práticas educativas de Ozildo Albano no Piauí}

Ozildo Albano empreendeu os seus esforços na tentativa de levar aos sujeitos do seu tempo saberes dos mais variados possíveis. Por onde exerceu o magistério dotou as sociedades de experiências culturais e educacionais voltadas para os valores e tradições do homem simples do sertão piauiense.

Dentre os eventos culturais realizados por Ozildo Albano, nos municípios piauienses de Picos, Pio IX e Jaicós, ressalta-se os blocos temáticos que desfilavam no sete de setembro, as quadrilhas juninas realizadas anualmente, as peças teatrais de escritores respaldados pelas academias literárias, o pastoril e demais atividades que faziam parte do calendário das escolas que lecionava. 
Por ser portador de um capital cultural reconhecido pela sua gente, em abril de 1983, Ozildo Albano foi nomeado pelo prefeito Abel de Barros Araújo para ocupar o cargo de Chefe de Departamento Municipal de Cultura do município de Picos, ficando no exercício de suas atribuições até o dia 08 de julho de 1985, quando pediu demissão.

Durante o período em que esteve à frente do Departamento Municipal de Cultura, Ozildo Albano organizou semanas de cultura e procurou resgatar as raízes folclóricas que estavam adormecidas. E mais, mostrou para a sociedade picoense as riquezas artísticas que atravessaram as gerações de homens que se formaram às margens do Vale do Guaribas.

Vale destacar que na II - Semana de Cultura de Picos, realizada por Ozildo Albano, entre 18 e 24 de julho de 1983 , ele fez questão de levar para os picoenses uma galeria de atrações que mostravam um pouco do que tinha a sua terra natal. A programação contemplava, dentre outras atrações, apresentações de sanfoneiros, banda de músicas, violeiros, poetas, repentistas, grupos teatrais, grupo folclórico de São Gonçalo, exposição de quadros de pintores da terra, exposições de artesanatos, palestra sobre literatura piauiense, atrações como corridas rústicas e concurso de fantasias de Jegue.

Mesmo depois que deixou o Departamento Municipal de Cultura, Ozildo Albano continuou incentivando a cultura local, a prova disso é que em 1985 criou com amigos o Grupo Mutirão Arte e Cultura. Um grupo voltado para a preservação das tradições artísticas e culturais, o qual também tinha como foco de atenção valorizar os artistas da terra.

Vocacionado ao labor da pesquisa e da busca incansável por objetos antigos e documentos que registravam acontecimentos históricos dos piauienses, Ozildo Albano foi o responsável pela organização e fundação do Museu Capitão-Mor João Gomes Caminha, em 1966. Segundo a sua amiga e artista plástica Mundica Fontes, em homenagem póstuma:

Este entusiasta da cultura franqueou à comunidade picoense o espaço do Museu-Biblioteca Capitão-Mor João Gomes Caminha principalmente aos estudantes e pesquisadores, a quem atendia pessoalmente. Posteriormente, em nova residência, Ozildo transferiu também o museu, que passou a funcionar à Rua São Francisco, 500, em espaço mais favorável ao público (ALBANO E SILVA, 2011, p. 22).

Em matéria publicada no Jornal Macambira, edição do dia 31 de agosto de 1981, Ozildo Albano afirmou que o museu teve início com os arquivos de objetos que pertenceram a um dos seus ancestrais, João Gomes Caminha, e que o museu recebeu o seu nome como 
uma das formas de homenageá-lo, uma vez que ele participou ativamente da Guerra de Independência e por ter colaborado na vida histórica do município de Picos.

Ozildo Albano acrescentou ainda que a sua coleção era composta por fotografias, objetos sacros, armas do tempo do Brasil Colônia, Império e República, fotografias, quadros, objetos fósseis e, somando-se a isso, destacou que havia documentos assinados por Fidié, comandante das armas portuguesas no Piauí.

Por derradeiro, informou que o objeto mais antigo da sua coleção era uma candeia de azeite, do primeiro século da era cristã e que chegou às suas mãos por intermédio de seu irmão que havia conseguido em Roma, entre os frades cistecenses. Outra informação que deixou registrado no jornal é que o documento mais antigo que ele tinha datava de 1785 , sobre a arrecadação de dízimos da Freguesia de Marvão.

No início, Ozildo Albano não tinha um espaço adequado para colocar os artefatos museais. Ele mantinha guardava em baús, na casa de seus pais, que se localizava na Avenida Getúlio Vargas, $n^{\circ}$ 285, em Picos. Ele sabia do significado de cada objeto semióforo. Quando alguém ia visitá-lo ou sabia que ele colecionava peças antigas, fazia questão de mostrar o seu pequeno acervo.

Foi nesse primeiro espaço que Ozildo Albano começou a educar por meio de seu patrimônio cultural. Posteriormente, mudou-se para a Rua São Francisco, no 500, um lugar mais adequado ao público visitante. $\mathrm{E}$ foi nessa espacialidade que passou a organizar melhor os objetos e documentos que guardava em baús.

O interesse de Ozildo Albano para o colecionismo não parou por aí. Ao saber que o município de Picos estava tomando ares de civilidade e as famílias estavam se desfazendo de objetos antigos, tomou a iniciativa de recolhê-los. Segundo o historiador Duarte (1995, p.59),

\begin{abstract}
O início da década de 50 foi marcado pela introdução de alguns objetos que não só contribuíram para a melhoria do padrão de vida daqueles que podiam adquiri-los, como tiveram um forte impacto sobre certos hábitos que remontavam há vários séculos. Seguindo uma tendência que se propagava a partir das grandes cidades, Picos foi conhecendo certos símbolos de progresso e de conforto, como o fogão de ferro, a geladeira a querosene, a pia e a bacia sanitária, chamada de sifon, os jipes das marcas Land Rover e Wyllis Overland, e até as bicicletas para adolescentes, das marcas Raleigh, Philips, Bristol, Merckswiss e Gulliver. Esses objetos eram, obviamente, restritos às famílias de maiores posses e eram motivo de curiosidade para aqueles que não tinham condições de adquiri-los.
\end{abstract}

Vendo as mudanças que estavam acontecendo no enredo urbano de Picos, Ozildo Albano tratou de garimpar os objetos antigos que foram sendo descartados pelos seus 
contemporâneos. Muitos moradores não conseguiam enxergar o descarte de raridades históricas, mas, ele via a importância que havia por trás das várias peças e, quando passava a ter a posse delas, colocava-as expostos no seu museu particular.

Quando Ozildo Albano fazia essa transposição do objeto do campo utilitário para a sua entrada na cadeia museal, oportunizava à peça assumir um novo status, o de objeto semióforo que, segundo Pomian (1984, p.71) enquadra-se como sendo “[ [...] objetos que não têm utilidade [...] mas representam o invisível, são dotados de significados; não sendo manipulados, mas expostos ao olhar, não sofrem usura. [...]”.

Dessa forma, cada semióforo que Ozildo Albano apresentava ao visitante trazia consigo uma historicidade e um significado para aqueles que o tinham no convívio diário. E, quando fazia isso, ele educava por intermédio das suas mediações.

Torna-se oportuno destacar que Ozildo Albano era um intelectual mediador cultural. Entendendo a noção de intelectual na acepção de Sirinelli (2003, p.242), como sendo:

\footnotetext{
[…] uma definição de geometria variável, mas baseada em invariantes. Estas podem desembocar em duas acepções do intelectual, uma ampla e sociocultural, englobando os criadores e os 'mediadores' culturais, a outra mais estreita, baseada na noção de engajamento. No primeiro caso, estão abrangidos tanto o jornalista como o escritor, o professor secundário como o erudito. Nos degraus que levam a esse primeiro conjunto postam-se uma parte dos estudantes, criadores ou 'mediadores' em potencial, e ainda outras categorias de 'receptores' da cultura. […].
}

Por ter difundido e viabilizado o conhecimento aos sujeitos do seu tempo, Ozildo Albano se encaixava na acepção ampla e sociocultural de intelectual. Foi dessa instância de consagração que ele estabeleceu uma ponte entre a alta cultura e a popular, assim, fazendo a mediação cultural.

\section{Considerações Finais}

Ter registrado a escrita educativa e cultural do educador Ozildo Albano, em terras piauienses, por meio de relatos de agentes históricos que conviveram e presenciaram as suas práticas educativas, não só trouxe informações particulares de uma vida, mas um modelo educacional que se inscreveu na História da Educação do Estado.

Ozildo Albano fez parte da intelligentsia piauiense e tornou-se uma referência nos municípios por onde exerceu a docência. Era um homem culto e possuidor de uma formação 
humanística que deu a ele o ingresso em um campo de produção simbólica e, a partir dele, passou a fazer a mediação cultural em espacialidades marcantemente assoladas pelo atraso em diferentes setores sociais.

Foi por intermédio dos eventos organizados por Ozildo Albano que os piauienses foram agraciados com enredos culturais, que se encontravam esquecidos no tempo. Durante a sua trajetória de vida, ele resgatou as mais simples manifestações folclóricas de sua gente e colocou-as novamente em evidência, mostrando assim, o homem de cultura que estava a serviço de um projeto educativo.

\section{Referências}

ALBANO, Maria da Conceição Silva e SILVA, Albano (Orgs.). Picos nas anotações de Ozildo Albano. Picos-PI: Gráfica Brito, 2011.

BOURDIEU, Pierre. A ilusão biográfica. IN.: FERREIRA, Marieta de Morais e AMADO, Janaína (Orgs.). Usos e Abusos da História Oral. Rio de Janeiro: Editora FGV, 2006.

Os três estados do capital cultural. IN.: BOURDIEU, Pierre. Escritos de educação. 9 ed. Petrópolis: Vozes, 2007.

DUARTE, Renato. Picos: os verdes anos cinquenta. 2 ed. rev. ampl. Recife: Gráfica Ed. Nordeste, 1995.

ECO, Umberto. Seis passeios pelos bosques da fiç̧ão. Trad. HildegardFeist. São Paulo: Companhia das Letras, 1994.

Porto, 1993.

Leitura do texto literário- LECTOR IN FABULA. Trad. Mário Brito. Lisboa: 2 ed.

POMIAN, Krzysztof. Colecção. IN.:ENCICLOPÉDIA EINAUDI: MEMÓRIA-HISTÓRIA 1. Trad. Suzana Ferreira Borges. Imprensa Nacional - Casa da Moeda, 1984.

SIRINELLI, Jean-François. Os intelectuais. IN.:Por uma história política. Trad. Dora Rocha. 2 ed. Rio de Janeiro: Editora FGV, 2003.

\section{Fontes orais}

ALBANO, Maria da Conceição Silva. Entrevista concedida ao pesquisador Welbert Feitosa Pinheiro. Picos-PI, 14 de fev de 2017.

ALBANO, Maria Vanilda. Entrevista concedida ao pesquisador Welbert Feitosa Pinheiro. PicosPI, 22 de nov de 2017. 
Revista Educação e Políticas em Debate - v. 7, n. 3, p. 470-481, set./dez. 2018 - ISSN 2238-8346

SOUZA, Elízio Serafim de. Entrevista concedida ao pesquisador Welbert Feitosa Pinheiro. PicosPI, 12 de ago 2016. 